\title{
O GRANDE AUSENTE DA EDUCAÇÃO MATEMÁTICA E A ALIENAÇÃO NA EDUCAÇÃO ESCOLAR
}

\author{
LA GRAN AUSENCIA DE LA EDUCACIÓN MATEMÁTICA Y LA ALIENACIÓN EN LA \\ EDUCACIÓN ESCOLAR
}

\section{THE GREAT ABSENT OF MATHEMATICAL EDUCATION AND ALIENATION IN SCHOOL EDUCATION}

\author{
Guilherme Wagner ${ }^{1}$ \\ Everaldo Silveira ${ }^{2}$
}

Resumo: A alienação por muito tempo foi considerada uma temática revisionista no campo marxista sendo pouco explorada em Educação Matemática (EM). Partindo da alienação como categoria marxista analisamos a Teoria da Objetivação chegando à conclusão de que esta se equivoca ao ignorar a luta de classes como categoria analítica na educação escolar desembocando numa postura pedagógica idealista. Por fim defendemos duas tarefas para a TO na perspectiva da revolução socialista: tomar a luta de classes como central na análise concreta da realidade da sala de aula de matemática e articular suas estratégias pedagógicas de superação da alienação com as lutas mais amplas da classe trabalhadora.

Palavras-chave: Alienação. Educação Matemática Escolar. Teoria da Objetivação.

Resumen: La alienación durante mucho tiempo fue considerada un tema revisionista en el campo marxista, siendo poco explorada en la Educación Matemática (EM). Partiendo de la alienación como una categoría marxista, analizamos la Teoría de la Objetivación, concluyendo que está mal ignorar la lucha de clases como una categoría analítica en la educación escolar, lo que resulta en una postura pedagógica idealista. Finalmente, defendemos dos tareas para el TO en la perspectiva de la revolución socialista: tomar la lucha de clases como central en el análisis concreto de la realidad del aula de matemáticas y articular sus estrategias pedagógicas para superar la alienación con las luchas más amplias de la clase trabajadora.

Palabras clave: Alienación. Educación Matemática Escolar. Teoría de la objetivación.

Abstract: Alienation for a long time was considered a revisionist theme in the Marxist field, being little explored in Mathematical Education (MA). Starting from alienation as a Marxist category, we analyzed the Theory of Objectification, concluding that it is wrong to ignore the class struggle as an analytical category in school education, resulting in an idealistic pedagogical posture. Finally, we defend two tasks for the TO in the perspective of the socialist revolution: to take the class struggle as central in the concrete analysis of the reality of the mathematics classroom and to articulate its pedagogical strategies to overcome alienation with the broader struggles of the working class.

Keywords: Alienation. School Mathematics Education. Objectification Theory.

\section{Introdução}

A temática da alienação durante muito tempo foi considerada no campo marxista um estudo revisionista da teoria marxiana, resquícios imaturos e hegelianos do jovem Marx e um exacerbado idealismo e subjetivismo dos "filósofos". Estes argumentos foram se desenrolando durante grande parte do período stalinista em que imperava o que ficou conhecido como $D I A M A T^{3}$ (KOHAN, 2003). 
Para um estudo mais aprofundado do que é a alienação na educação matemática escolar estaremos nos apoiando em quatro autores que discutiram ou a educação, ou a alienação: Lukács, Mészáros, Suchodolski e Marx. Entendemos que a categoria da alienação "exprime formas de modos de ser, determinações da existência” (MARX, 1982, p. 18), ou seja, as categorias para o pensamento marxista não são construtos ideais que se comparam a materialidade, mas reflexo da materialidade na consciência a partir de um processo ativo da subjetividade cognoscente (LUKÁCS, 2013).

Desta forma, procuramos compreender de que forma a alienação do trabalho se configura no pensamento marxiano, principalmente a partir dos Manuscritos de 1844, e sua manifestação na realidade. Com Lukács (2013) faremos uma diferenciação analítica de um processo unitário da práxis em geral, originária do trabalho como pôr teleológico, entre objetivação e exteriorização/alienação. Desses pressupostos nos aproximamos da análise da educação a partir de Mészáros (2012, 2016) e Suchodolski (1976) para pensar meios de superar a alienação na e com a educação.

A teoria da Objetivação (TO) adentra ao nosso campo por elaborar coerentemente uma proposta teórico-metodológica de superação ou combate a alienação nas salas de aula de matemática da educação escolar. Entretanto, procuraremos evidenciar que a compreensão de alienação dessa perspectiva se mantém presa a uma concepção hegeliana e por seguinte desemboca no silenciamento de uma fundamental categoria marxista na luta anti-alienação, que aqui chamamos a grande ausente, as lutas de classes. Para o desenvolvimento desse diálogo crítico com a TO analisaremos os trabalhos de seu principal referencial, Luis Radford.

\section{A Alienação nos Manuscritos de 1844}

Nos manuscritos de 1844 Marx faz uma análise da forma como o dinheiro e a mercadoria impactam a vida dos trabalhadores. A partir dessa análise ele constata quatro aspectos da alienação do trabalho: 1) a alienação do trabalhador com relação ao produto do seu trabalho; 2) alienação do trabalhador com relação ao trabalho enquanto atividade produtiva e criativa; 3) alienação do trabalhador com relação ao gênero humano; e 4) alienação do trabalhador com relação aos indivíduos do Ser Social.

Segundo Suchodolski (1976), Marx compreende em sua análise das relações fetichizadas da mercadoria e na imperiosidade do cotidiano dominado pelo dinheiro que os humanos se afastam de sua verdadeira humanidade assumindo para si uma humanidade coisificada, falsa, que avilta sua personalidade.

Mészáros (2016) afirma que nesses manuscritos já está presente a defesa intrínseca da relação dialética entre o que se convencionou chamar de infraestrutura e superestrutura. Isto é, em oposição ao que afirmava a DIAMAT soviética, não existe uma determinação causal entre a base econômica da sociedade e seus reflexos ideológicos. Segundo Mészáros (2012) o que Marx consegue compreender nesse momento é que a relação ontológica fundamental do trabalho humano como transformação direta da natureza (mediação de primeira ordem), enquanto metabolismo originário do Ser Social, passa a ser mediado pelas relações da propriedade privada e do trabalho assalariado, às mediações de segunda ordem. Isto é, não é a propriedade privada que inaugura a alienação do trabalho, mas a própria atividade humana do trabalho que 
vai estruturar as bases do trabalho alienado pelas mediações de segunda ordem, é por isto que falamos do trabalho alienado como uma autoalienação humana. Como o ser humano somente poderá transformar a natureza a partir das mediações de segunda ordem tanto a Indústria (complexo das forças produtivas) quanto a Natureza (complexo do Ser Natural) estarão em uma relação alienada com o ser humano, e suas representações ideológicas serão reificadas:

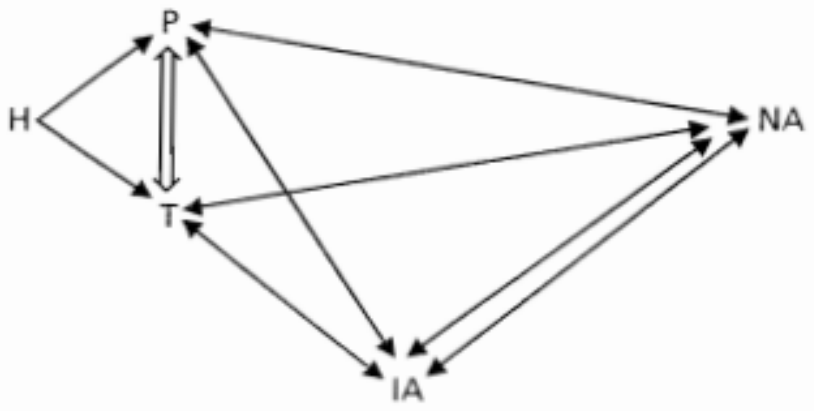

Figura 1: Mészaros (2016, p. 103)

Nesse diagrama, retirado de Mészáros (2016, p. 103), apresenta-se como ocorre o processo de autoalienação do trabalho na sociedade do capital. A relação do trabalho, relação sociometabólica do ser humano para a transformação da natureza, se dá de maneira mediada pela propriedade privada $(\mathrm{P})$ e pelo trabalho assalariado (T), portanto, a relação do ser humano com a Natureza e com a Indústria será uma relação alienada (NA e IA). Isto é, em Marx, a alienação se configura como um descompasso entre o desenvolvimento das forças produtivas com o desenvolvimento do ser humano enquanto ser social particular.

Em contraposição a ele, nas mediações de primeira ordem da gênese da sociedade humana enquanto Ser Social, Mészáros (2016, p. 100) entende que Marx estabelece as seguintes relações dialéticas:

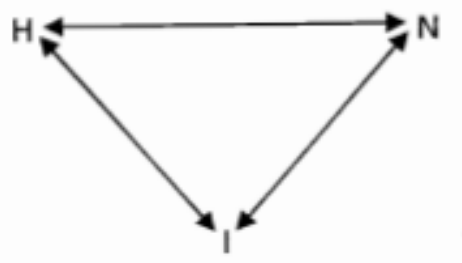

Figura 2: Mészaros (2016, p. 100)

Nesse diagrama temos que o Humano $(\mathrm{H})$ se relaciona dialeticamente com a Natureza $(\mathrm{N})$ e a Indústria (I) de maneira primitiva, e portanto, o trabalho exerce uma papel criativo-prazeroso e existe um desenvolvimento das forças produtivas (socialidade) e um desenvolvimento da personalidade humana (individuação).

\section{A Alienação em Lukács}

Seguindo a linha do pensamento marxiano Lukács (2013) identifica a alienação como a antítese entre o desenvolvimento das forças produtivas e dos indivíduos sociais, um descompasso entre o 
desenvolvimento das capacidades humanas do ser genérico com o desenvolvimento da personalidade humana particular.

A partir das categorias Entäusserung e Entfremdung, usadas por Marx em grande parte como sinônimos parciais de um processo unitário da alienação, Lukács (2013) fará uma cisão analítica do processo unitário de objetivação para compreender o fenômeno da alienação originária do trabalho. Para Lukács (2013) o trabalho é o protótipo de toda práxis social, e consequentemente, as diversas alienações (religiosas, morais, políticas, etc.) originam-se no processo do trabalho alienado, sem, no entanto, se reduzirem em absoluto a ele. O processo de realização do trabalho é um pôr teleológico, isto é, parte de uma causalidade natural para uma causalidade posta. Para que uma causalidade natural se torne em causalidade posta o processo de objetivação do pôr teleológico necessita que o sujeito faça escolhas entre alternativas materialmente possíveis. A objetivação do processo de trabalho em um objeto final é necessariamente um processo teleológico, peculiaridade do Ser Social.

\section{Causalidade Natural OBJETIVAÇÃO Causalidade Posta Objeto Natural \\ Objeto Social}

Figura 3: Os Autores.

No entanto, o processo de objetivação sempre retroage sobre o sujeito que o põe em movimento fundando-se assim a subjetividade humana, a individualidade da personalidade humana, este é o processo de exteriorização (Entäusserung ${ }^{\star}$ ), isto é, o momento do trabalho em que o sujeito que põe exterioriza sua personalidade/subjetividade em uma materialidade e é influenciado por ela reconfigurando sua própria subjetividade. A escolha entre alternativas é um dos momentos do trabalho que expõe a personalidade do sujeito que põe, no entanto, diferente da objetivação que tem como produto um objeto final dotado de certa homogeneidade, a exteriorização impacta a formação da subjetividade humana de formas muito diversificadas, podendo ocorrer um descompasso entre os dois desenvolvimentos.

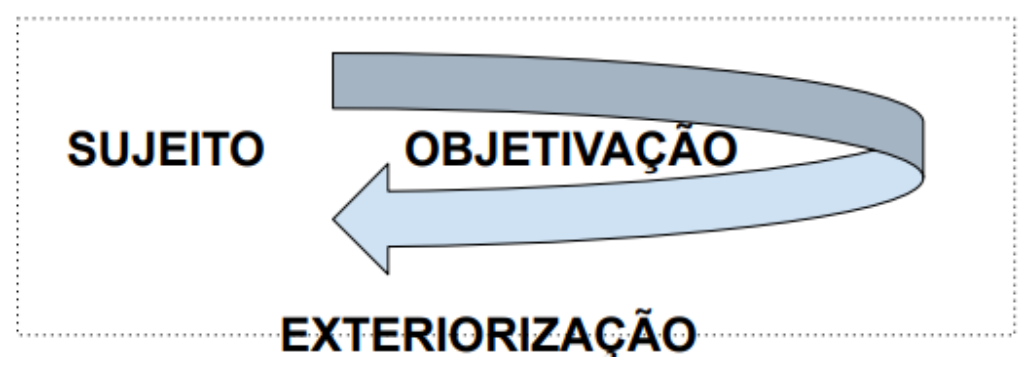

Figura 4: Os Autores

Este processo unitário do trabalho como objetivação e exteriorização constituem para Lukács (2013) a base fundamental de pólos ontológicos do ser sócio-histórico: a socialidade e a individuação. A objetivação contínua promove o avanço das forças produtivas do Ser Social (socialidade), enquanto a exteriorização, nas escolhas entre alternativas materialmente dadas, desenvolve os indivíduos singulares 
fazendo emergir a personalidade humano-social. Este processo que constitui no desenvolvimento contínuo tanto das forças produtivas quanto da personalidade humano-social é característica do trabalho ontológico, criativo, não-alienado. Entretanto, na sociedade capitalista todo trabalho é trabalho alienado pelas mediações de segunda ordem e consequentemente inaugura um descompasso entre os processos de socialidade e individuação.

Isto é, com o avanço das forças produtivas desenvolvem-se novas capacidades humanas, entretanto, esse desenvolvimento de capacidades humanas na sociedade de classes é feito mediante um processo no qual os indivíduos são sacrificados, pois o desenvolvimento das capacidades humanas de produção e transformação não produz obrigatoriamente o desenvolvimento da personalidade humana. Esta é a alienação, processo em que a personalidade humana é desfigurada/aviltada pelas capacidades singulares, privadas.

O trabalho manufatureiro constituiu um exemplo importante desse processo de alienação do trabalho, pois não desenvolveu a personalidade humana. Na manufatura moderna o desenvolvimento das forças produtivas equaliza humano e máquina como meros instrumentos fragmentários da produção, desta forma o potencial humano relativo ao pensamento, à criação, ao crescimento das suas habilidades fica limitado ao exercício repetitivo do indivíduo como fragmento do processo produtivo. Em suma, no processo de alienação apesar do desenvolvimento das forças produtivas pode ocorrer uma regressão/involução da personalidade humano-social.

Diante do exposto podemos localizar na exteriorização a base de referência para compreender a alienação, entretanto, diferente de Hegel que equipara exteriorização e alienação como uma identidade positiva da consciência como autoconsciência objetiva, a alienação no pensamento marxista é um fenômeno objetivo primordialmente centrado no indivíduo com forte relação dialética com o Ser Social. Por outro lado, ao mesmo tempo que a exteriorização é um veículo de reprodução da alienação, ela é também um possível veículo de superação da alienação (LUKÁCS, 2013).

Para Lukács (2013) a gênese da alienação como negatividade da formação subjetiva humana nos processos de objetivação do trabalho ocorre com a apropriação de mais-valor, na produção excedente do trabalho, em que o excedente passa a ser apropriado por determinados setores sociais fazendo emergir aqueles que trabalham para que outros possam usufruir (escravidão). Este descompasso entre apropriação do trabalho excedente e produção social inaugura o descompasso dos desenvolvimentos de capacidades humanas singulares em detrimento de outras fazendo entrar a alienação na vida:

[...] a escravidão, como primeira forma de desigualdade, fundada no terreno socioeconômico e imposta entre os membros da sociedade, tem sua base no fato de que o escravo está em condições de produzir mais do que é necessário para sua própria reprodução, e que por isso seu possuidor está socialmente na condição de dispor desse mais-trabalho para satisfazer suas próprias necessidades pessoais. Com isso, o estranhamento [alienação] entra na vida (LUKÁCS, 2013, p. 246)

Portanto, a alienação do trabalho é sempre uma autoalienação do ser humano sobre si que na sociedade capitalista é produzida pelas mediações de segunda ordem (MÈSZAROS, 2016). A questão que se põe agora é como a alienação se manifesta na educação escolar. 


\section{A Alienação na Educação Escolar}

Ao retomarmos os quatro aspectos pelos quais o trabalhador assalariado, proletário, se aliena vistos na primeira seção será possível traçar um paralelo com a Escola. Enguita (1989) afirma que como os trabalhadores não dispõe dos meios de produção do seu trabalho, assim também os estudantes não possuem os meios de trabalho de sua aprendizagem, pois estes não se reduzem ao lápis, ao caderno, etc. Por outro lado, no que concerne a aprendizagem não faz sentido posicionar a problemática em questões de posse, mas de controle. Os estudantes, afirma Enguita (1989), não dispõe do controle sobre os meios de seu trabalho escolar que se manifesta na disposição dos meios físicos de espaço e equipamento, "tudo na escola parece estar organizado para que os alunos não possam desenvolver sentido algum de posse ou controle" (ENGUITA, 1989, p. 184): espaços transparentes, pátios de recreio vigiados, entrada ao espaço escolar controlada, inculcação de valores que afirmam que o espaço da escola não é deles, o uso de equipamentos do laboratório, projetores, etc, encontram-se trancafiados e são pouco utilizados para não ter desgaste físico.

O processo de ensino-aprendizagem na educação escolar pode ser compreendido como uma tétrade dialética entre conteúdos/formas, professor, educando e ambiente e todas essas dimensões adentram à análise da alienação na educação escolar. Os conteúdos/formas e referem tanto aos conhecimentos historicamente acumulados pela humanidade (SAVIANI, 2018) quanto pelas opções pedagógicas feitas durante o processo de ensino-aprendizagem da escola, das aulas, do ambiente como um todo. O professor é entendido como o indivíduo que zela pelo processo de ensino-aprendizagem no educando no ambiente escolar.

\section{PROFESSORES}

\section{CONTEÚDOS/ FORMAS}

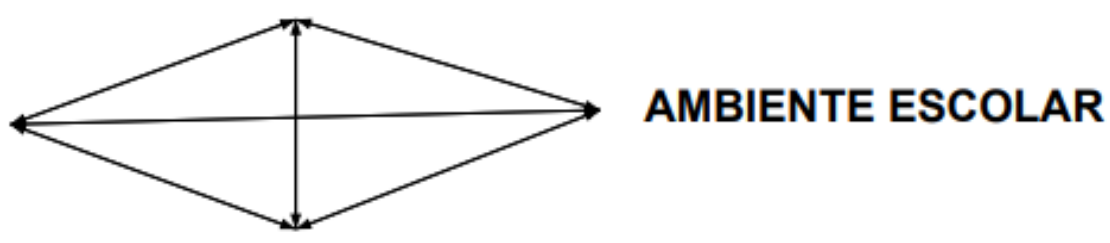

EDUCANDO

Figura 5: Os Autores

Segundo Lukács (2013) a práxis educativa é um pôr teleológico secundário, pois busca agir sobre a subjetividade de outros seres humanos a fim de que eles realizem determinada prática social pré-definida pelo sujeito que põe. Em suma, a objetivação na práxis educacional, quando observamos do ponto de vista do professor, se refere a uma objetivação não no plano objetivo, mas no plano subjetivo de outro sujeito, o educando. Por outro lado, o processo de aprendizagem do educando pode ser compreendido como uma auto-objetivação de um conhecimento.

No processo de auto-objetivação, entendido como uma práxis de aprendizagem do educando, a atividade de se apropriar de determinado conhecimento científico acumulado pela humanidade pode ser entendido como trabalho não-material em que o produto do trabalho não se separa do ato de produção (SAVIANI, 2011). Portanto, dado que a escola reproduz em larga medida a relações alienantes da sociedade 
capitalista (MÉSZÁROS, 2012; ENGUITA, 1989) a alienação do processo de aprendizagem também apresenta as quatro manifestações do trabalho alienado: 1) o educando é alienado frente o conhecimento que está aprendendo; 2) o educando é alienado do processo educativo; 3) o educando é alienado da humanidade que produziu tal conhecimento; e 4) o educando é alienado frente aos colegas partícipes do processo educativo. Entre as características mais evidentes desse processo de alienação pode ser no paralelo entre o sistema de notas e o sistema de dinheiro, onde os educandos reduzem suas capacidades, seu trabalho educativo, sua auto-objetivação enquanto ato produtivo, àquilo que possa ser trocado pelas notas suficientes que lhe permitam o avanço na vida escolar. Seu salário é quantificado em um ranking de notas.

Este processo de alienação do educando no processo educativo estabelece o empobrecimento da formação singular de sua personalidade humana, onde os espaços restritos da escola, a forma de ensino, os conhecimentos bancários, acabam limitando a aprendizagem do educando como um simples repetir de habilidades da mesma forma que a maquinaria restringiu o desenvolvimento da personalidade humanosocial. Isto é, um processo que impede que a humanização do sujeito singular (DUARTE, 2013), em detrimento das competências esperadas e reguladas pelo capital.

Por outro lado o trabalho educativo do professor é alienado pois restringe as formas e conteúdos com os quais busca humanizar seus educandos, isto é, limitados pelo currículo, pelas avaliações em larga escala, pelo sistema de notas e pelas exigências de aprovações os professor acabam repetindo mecanicamente as habilidades estandardizadas pelo capital, desumanizando seus educandos e deixando de desenvolver sua própria subjetividade ao não identificar seus educandos como indivíduos singulares do gênero humano, mas como espectros coisificados de resultados quantificáveis.

A esse processo educativo que busca inculcar valores, hábitos e competências que propiciem a reprodução ampliada do capital Mészáros (2012) define como a função da escola capitalista: internalização. Isto é, uma inculcação de que a posição ocupada pelos indivíduos na hierarquia social é legítima, adequada e correta. Quando a internalização é funcional a violência e a brutalidade como meios educativos são colocados em segunda ordem, mas eles sempre podem reaparecer como instrumento de controle e internalização de valores. O processo de internalização, essência da educação alienada sob a égide do capital, busca produzir nos indivíduos habilidades necessárias para gerir a economia capitalista e formar quadros e elaborar métodos de controle político.

Para Mészáros (2012) esse processo internalização não é próprio da educação escolar, mas da educação em sentido amplo, visto que o espaço escolar não é a via primordial para a internalização desses valores e hábitos, assim como também "não fornece uma alternativa emancipadora radical” (p. 45).

\section{A Superação da Autoalienação e o papel da Educação Escolar}

Em suma, Mészáros (2012) afirma que se necessita de uma mudança da totalidade do sistema de internalização do capital, não bastando negar simplesmente a educação existente, pois no processo de negação sempre nos mantemos presos ao objeto negado. Por outro lado, a efetiva transcendência da autoalienação do trabalho é essencialmente uma tarefa educacional, pois para que ela ocorra os seres 
humanos devem mudar "completamente as condições da sua existência industrial e política, e consequentemente, toda a sua maneira de ser" (MARX, apud MÉSZÁROS, 2012, p. 59). Isto é, não há possibilidades de reformas graduais e educacionais que possam superar a autoalienação.

Suchodolski (1976) concorda que a revolução seja uma necessidade imperiosa na superação da relações objetivas alienadas, no entanto, reforça que mesmo que estas sejam superadas imediatamente a inculcação e a desumanização proporcionadas por elas anteriormente ao Ser Social podem novamente objetivar-se em novas formas alienadas. Portanto, o embate contra a alienação é duplo, pela transformação radical das relações alienadas, e, ideológico combatendo teoricamente todas as filosofias reificadas da classe dominante e àqueles que identificam a superação da alienação como papel autoconsciente da humanidade. Assim:

A educação deve esforçar-se não só porque a consciência humana esteja adequada a vida real, concreta, mas deve procurar também que esta vida, ao superar-se a alienação contenha a necessária forma mediante «propriedades genéricas» essenciais do homem e que assim a consciência evolucione e se aperfeiçoe. (SUCHODOLSKI, 1976, p. 208)

Para Duarte (2013) o processo de alienação é sempre contraditório, inclusive na educação escolar, e, portanto, sempre existem possibilidades de humanização dos indivíduos singulares. Lukács (2013) ao demonstrar que o veículo da superação também perpassa a exteriorização, enquanto processo unitário da objetivação que retroage sobre o sujeito que põe, evidencia o papel das escolhas entre alternativas feitas pelos sujeitos (seja singulares, seja em classes) e que estas escolhas sempre podem direcionar-se ou para a reprodução do capital ou para a contestação/revolução, assim o papel ideológico da educação na luta pela superação da autoalienação do trabalho sob a égide do capital é demonstrado como fundamental enquanto totalidade social e dialeticamente subordinado às relações objetivas.

\section{A Teoria da Objetivação: o grande ausente e a alienação}

A Teoria da Objetivação (TO) é uma perspectiva que desenvolve a Teoria Histórico-cultural dentro do campo da Educação Matemática (RADFORD \& ROTH, 2011) seguindo uma linha sociocultural de pesquisa (RADFORD, 2016a). A exposição completa de sua fundamentação teórica não é o objetivo desse artigo ${ }^{5}$, o foco está direcionado nos aspectos teóricos utilizados pelos seus autores para elaborar uma concepção de alienação na educação matemática escolar. Segundo Radford (2016a) a TO parte de uma outra intepretação sociocultural da Educação Matemática, diferente da linguagem de base bakhtiniana, compreendendo-a como uma atividade humana. Nessa perspectiva faz-se um convite para entender o processo de ensino-aprendizagem de professores e estudantes como sendo aquilo que eles "se engajam nas atividades de sala de aula" (RADFORD, 2016a, p. 2). Parte-se do princípio de que o ser humano é um ser de necessidades e que precisa suprir tais necessidades, e para tanto se desenvolve todo um complexo social para a produção de objeto que satisfazem tais necessidades. Nesse processo de produção os indivíduos expressam sua individualidade (RADFORD, 2016b), e o primeiro movimento, que vai se mostrar o principal para TO, entende que a alienação seria justamente o fato do objeto produzido não ser mais uma expressão individual 
Em outras palavras, alienação é a perda da objetivação. A perda de objetivação - isto é, a perda de auto-expressão no objeto - só pode ser alienante para uma espécie, como a nossa, para a qual a objetividade faz parte de sua natureza. Em vez de expressão, conquista e auto-realização, temos um produto que se torna uma coisa. (RADFORD, 2016b, p. 6, tradução nossa)

O segundo momento, que emerge da objetivação individual alienada, seria o trabalho alienado, para em seguida aparecer as alienações entre as relações sociais e de indivíduos com outros indivíduos. Isto é, a primazia está no processo individual do sujeito, permeado pela cultura, de uma objetivação alienada. Como lembramos anteriormente, a alienação tem no indivíduo sua gênese, entretanto guarda uma forte relação dialética com o Ser social. Para Radford se expressa uma primazia do indivíduo nessa relação.

Apesar das tentativas de Radford e Roth (2017) advogarem que não existe uma sobredeterminação do indivíduo sobre a estrutura social na atividade humana alienada, a proposição pedagógica para a sala de aula de matemática demonstra outra crença. Este processo de ensino-aprendizagem que combate a alienação na educação matemática escolar passaria pelo que Radford (2016a) concebe como trabalho conjunto entendido como um "esforço coletivo e crítico de realização mútua e de autorrealização [baseado numa] ética comunitária” (p. 3, tradução nossa)

Para Radford (2016a) o trabalho conjunto é uma forma de estabelecer uma atividade pedagógica em educação matemática não-alienada, pois nesse microespaço da sala de aula aparece

um espaço de encontros, dissidência e subversão, onde professores e alunos se tornam os indivíduos que são mais do que no mundo - são indivíduos com um interesse um no outro e no seu empreendimento conjunto; indivíduos que intervêm, transformam, sonham, apreendem, sofrem e esperam juntos. (RADFORD, 2016a, p. 6, tradução nossa)

Estas novas relações individuais, propiciadas por uma sala de aula de trabalho conjunto seria a formação de uma nova ética, uma ética comunitária. A partir dessa nova ética comunitária estabelecida pelos indivíduos seria possível combater as alienação na educação escolar, em especial na sala de aula de matemática. O problema dessa abordagem da alienação na educação escolar está na incorreta interpretação da particularidade como totalidade, e da totalidade como resultado lógico-histórico da particularidade. Isto é, há uma inversão dos fundamentos de reprodução da alienação da sala de aula. Para o pensamento marxista o processo de análise deve sempre partir da totalidade social, a questão é que para a TO a sala de aula se torna totalidade social, enquanto ela é expressão particular das relações alienadas de toda socialidade humana sob a égide do capital. Dessa problemática surge a proposição abstrata da construção de uma nova ética, pautada na postura comunitária, a partir da sala de aula para assim estabelecer novas formas de relação nãoalienadas entre os indivíduos, combatendo o papel de internalização dos valores da sociedade capitalista. Entretanto, o papel educativo de internalizar os valores e habilidades necessários a sociedade capitalista não é especificidade da educação escolar, mas da educação em sentido amplo. Desta forma, a estratégia pedagógica de construir novas relações éticas a partir da sala de aula de matemática acabam esbarrando na realidade material do capitalismo.

Entretanto, a perspectiva da TO não está de todo equivocada, sua fraqueza está em se isolar frente as outras demandas de luta anticapitalista da classe trabalhadora. Em suma, o erro tático e estratégico do pensamento pedagógico da TO está num grande ausente de suas análises da totalidade: as lutas de classes. 
Esta perspectiva esterilizada da atividade educativa nas salas de aula de matemática da TO já fora denunciada por Pais (2017), o posicionamento da classe trabalhadora em luta contra seus trabalhadoras não se faz presente nas análises da alienação escolar de Radford.

Os impactos dessa ausência são uma perspectiva individualista, apartada da totalidade social e uma estratégia pedagógica de emancipação humana deslocada das demandas mais gerais da classe trabalhadora que se quer emancipar. Ao limitar sua análise concreta a situação particular da sala de aula de matemática a TO acaba confundindo uma assimilação correta do objeto conceitual matemático com uma objetivação não alienada do educando. Entretanto, é necessário lembrar que a alienação se caracteriza justamente pelo descompasso entre o ser particular e o ser genérico, se de um lado a apreensão do conhecimento científicomatemático pelo educando constitui um combate a alienação, de outro o não questionamento desse conteúdo matemático assimilado pode inculcar outros valores alienantes e fundamentais para a reprodução da ordem do capital, a saber o formalismo matemático. Segundo Mészaros (2009) o formalismo é uma das estruturas ideológicas do pensamento filosófico-científico mais importantes para a ordem do capital dado seu caráter de inculcar os valores da obediência à hierarquia. Em suma, relações individuais comunitárias que não questionam o conteúdo alienado que se está a aprender não combatem a alienação, mas a reforçam. Tal equívoco surge ao não considerar a totalidade da luta de classes na análise concreta dos conteúdos e das práticas pedagógicas em uma sala de aula de matemática.

A TO constitui-se em grande parte das produções teóricas de Vigotski e Leontiev, e como denunciado por Duarte (2001) algumas interpretações da teoria Historico-cultural acabam por ignorar o seu claro teor marxista e revolucionário desembocando em leituras ecléticas e liberais que sintetizam o pensamento de Vigotski com outros autores. Este parece ser um dos casos em tela, não poucas vezes Radford advoga a existência de um Vigotski spinoz̧iano (RADFORD \& ROTH, 2017) e de um marxismo spinoziano (RADFORD, 2016b). A compreensão de que seja possível uma leitura spinoziana desses leitores é que leva a TO em determinado momento a propor uma nova ética, como se esta emergisse do mundo das ideias e pudesse ser decretada na sala de aula, e da sala de aula para toda a sociedade.

\section{As tarefas da Teoria da Objetivação na perspectiva da Revolução}

Por mais que existam discordâncias frente a compreensão da alienação com a TO, tal perspectiva da Educação Matemática é hoje a mais avançada no que concerne a fundamentação de uma teoria pedagógica da educação matemática na perspectiva da classe trabalhadora: 1)ao compreender dialeticamente a subjetividade e a objetividade nas aulas de matemática, 2) ao se colocar como uma teoria que defende a centralidade das relações sociais coletivas frente as perspectivas escolanovista e cognitivistas, 3) ao se propor a discussão da emancipação humana numa perspectiva não liberal, 4) ao não negar suas bases marxistas.

Por outro lado, algumas tarefas se colocam frente aos equívocos analíticos da realidade concreta e nas proposições pedagógicas estabelecidas. É necessário, primeiro, que a Teoria da Objetivação para a educação matemática passe a tomar a luta de classes como central para o processo de ensino-aprendizagem, pois, a criticidade de um pesquisador em educação reside nessa postura (DUARTE, 2006). Segundo que 
passe a articular suas proposições pedagógicas com uma estratégia mais ampla de luta pela emancipação da classe trabalhadora, para que o trabalho conjunto da sala de aula de matemática esteja taticamente articulado com outras práticas que buscam a construção de uma alternativa social superando a autoalienação humana.

\section{Referências}

DUARTE, Newton. A pedagogia histórico-crítica e a formação da individualidade para si. Germinal: Marxismo e Educação em Debate, p. 59-72, 2013.

DUARTE, Newton. Vigotski e o" aprender a aprender": crítica às apropriações neoliberais e pós-modernas da teoria vigotskiana. Campinas: Editora Autores Associados, 2001.

ENGUITA, Mariano Fernández. A face oculta da escola: educação e trabalho no capitalismo. Artes Médicas, 1989.

KOHAN, Nestor. Marx en su (tercer) Mundo. Edit. Juan Marinello, La Habana, 2003.

LUKÁCS, György. Para uma ontologia do ser social II. Trad. Nélio Schneider. São Paulo: Boitempo, 2013.

MARX, Karl. Para a crítica da economia política; Salário, preço e lucro; O rendimento e suas fontes: a economia vulgar. 1982.

MÉSZÁROS, István. A educação para além do capital. São Paulo: Boitempo Editorial, 2012.

MÉSZÁROS, István. A teoria da alienação em Marx. Boitempo Editorial, 2016.

PAIS, Alexandre. The narcissism of mathematics education. In: The disorder of mathematics education. Springer, Cham, 2017. p. 53-63.

Radford, L. Mathematics Education as a Matter of Labor. In M.A. Peters (ed.). Encyclopedia of Educational Philosophy and Theory. Section: Mathematics education philosophy and theory. P. Valero and G. Knijnik, Editors. Singapore: Springer, 2016a.

RADFORD, Luis. Algunos desafíos encontrados en la elaboración de la Teoría de la Objetivación. PNA, v. 12, n. 2, p. 61-80, 2018b.

RADFORD, Luis. On alienation in the mathematics classroom. International Journal of Educational Research, v. 79, p. 258-266, 2016b.

RADFORD, Luis. Saber, aprendizaje y subjetivación en la Teoría de la Objetivación. $5^{\circ}$ Simpósio Internacional de Pesquisa em Educação Matemática-5º SIPEMAT, p. 1-22, 2018a.

RADFORD, Luis; ROTH, Wolff-Michael. Alienation in mathematics education: a problem considered from neo-Vygotskian approaches. Educational Studies in Mathematics, v. 96, n. 3, p. 367-380, 2017.

SAVIANI, Dermeval. Escola e democracia. Autores associados, 2018.

SAVIANI, Dermeval. Sobre a natureza e especificidade da educação. Em aberto, v. 3, n. 22, 2011.

SUCHODOLSKI, B. Teoria marxista da educação (Em três volumes). Lisboa: Estampa, 1976.

GOBARA, S.T., \& RADFORD, L. Teoria da Objetivação: Fundamentos e aplicações para o ensino e aprendizagem de ciências e matemática. São Paulo, Brazil: Livraria da Física, 2020.

\section{Notas:}

${ }^{1}$ Doutorando e Mestre em Educacao Cientifica e Tecnológica (UFSC), Graduado em Matemática (UFSC). Professor da Rede Municipal de Educacao de Florianópolis. Orcid: http://orcid.org/0000-0003-1346-7980 Email: guilherme.w@posgrad.ufsc.br

2 Professor Departamento de Metodologia de Ensino (CED/UFSC). Doutor em Educacao Científica e Tecnológica (UFSC), Mestre em Educacao Matemática (UFPR). Orcid: http://orcid.org/0000-0002-2113-2227 E-mail: derelst@hotmail.com 
3 A DIAMAT, ou materialismo dialético, foi a doutrina marxista hegemônica por boa parte do tempo na União Soviética. Segundo Kohan (2003) ela se afirmava como uma doutrina ontológica, da qual se tiravam conclusões gnosiológicas para todos os campos. Para o autor argentino, ao analisar a história da DIAMAT, ela se constitui numa justaposição ou soma do idealismo hegeliano com o materialismo de Feuerbach. Pensamentos que destoavam dessa interpretação era vistos como revisionistas e atentavam contra a ortodoxia.

${ }_{4}^{4}$ Alguns autores traduzem como Alienação, enquanto entendem que Entfremdung seria Estranhamento. No que concerne a esse trabalho entendo Entäusserung como exteriorização, e Entfremdung como Alienação.

5 Para uma fundamentação completa da TO sugere-se a leitura de Gobara e Radford (2020), Radford (2018a; 2018b)

Recebido em: 28.02.2020

Aprovado em: 23.05.2020 